\title{
Recurrent abdominal pain in children: A Sri Lankan perspective
}

\author{
Niranga M Devanarayana ${ }^{1}$ \\ Sri Lanka Journal of Child Health, 2010; 39: 79-92
}

(Key words: Recurrent abdominal pain, children, Sri Lanka)

\section{Foreword}

Good evening, Chief Guest, Professor Priyani Soysa, Guest of Honour, Dr. Timothy Chambers, President, Sri Lanka College of Paediatricians, Members of the Council, Ladies and Gentlemen. I thank you most sincerely for the honour you have given me by awarding the "Professor $\mathrm{C} \mathrm{C}$ de Silva Oration 2010". It is a great pleasure to speak about this great clinician, accomplished academic writer, and brilliant medical teacher who is known as the founding father of modern scientific paediatrics in Sri Lanka.

Percival Cholomondley Chalmers de Silva was born on $25^{\text {th }}$ February 1904. After finishing school, he entered the Ceylon Medical College in 1922, but after 2 years, he moved to Kings College Hospital, London and graduated MRCS LRCP in 1928. He completed his MRCP in 1931 and MD in 1938.

After returning to Sri Lanka he first settled down as a general practitioner in Colombo, but soon began to specialize in child health. In 1949, when the department of paediatrics was established at the University of Ceylon, he was appointed as the first professor of paediatrics of our country and occupied this chair until his retirement in 1966. When the second medical school was started at Peradeniya in 1964, Prof. C C de Silva took up the challenge of organizing the department of paediatrics and laboured tirelessly until it was fully established.

He was undoubtedly one of the greatest paediatricians in Sri Lanka who defies a single label. His main clinical interests were nutritional disorders, thalassaemias and infective diarrhoeas. His publications on kwashiorkor and typhoid fever are the first publications of these disorders from Sri Lanka. He has always stressed the importance of nutrition in preventing diseases. He helped to set up the first nutritional rehabilitation centre at Thalagolla, Ragama, which is situated next door to the Faculty of Medicine, University of Kelaniya, where I work. He was the president of the Ceylon

${ }^{1}$ Senior Lecturer, Department of Physiology, Faculty of Medicine, University of Kelaniya, Ragama, Sri Lanka branch of the British Medical Association in 1949 and the editor of the Ceylon Medical Journal from 1950 to 1952. Furthermore, he was the first secretary of the Ceylon Paediatric Association founded in 1952 and was the president of this association from 1956 to 1958 . He was also a pioneer in the field of family planning. He was the president of the Family Planning Association from 1956 to 1958 and again from 1976 to 1977 even after his retirement.

Prof. C C de Silva had many interests outside the field of medicine. One of them was travelling. His experience on his travel to Russia is expressed in his famous book, "Out Steppes the Don". Most important of all, his skill as an organizer and his gift of teaching have provided Sri Lanka a generation of doctors well trained in paediatrics.

The topic for the Prof. C C de Silva Oration is "Recurrent abdominal pain in children: a Sri Lankan perspective". First as a general practitioner, then as a paediatrician, childhood recurrent abdominal pain would have been a topic close to his heart.

\section{Introduction}

In 1909, a British paediatrician, G F Still wrote; "I know of no symptom which can be more obscure in its causation than colicky abdominal pain in childhood". Today, a century later, abdominal pain in children still remains a symptom which is often difficult to understand and managing it is a major challenge to paediatricians ${ }^{1}$. In some children, the episodes of abdominal pain may be severe enough to result in frequent visits to doctors, school absenteeism, poor concentration on studies, and inability to participate in sports and other extracurricular activities ${ }^{2}$.

In 1958, J Apley, another British paediatrician, studied abdominal pain among children extensively. He named this symptom complex as "recurrent abdominal pain syndrome of childhood" and defined it as "at least three episodes of abdominal pain, severe enough to affect their activities over a period longer than three months" 3 . His findings formed the main guidelines for the paediatricians and researchers dealing with this 
problem. Often the term chronic is misused when referring to recurrent abdominal pain (RAP) since each episode of pain is distinct and separated by periods of well-being.

According to previous epidemiological studies in the world RAP is the second common painful health problem in school-aged children, only second to headache ${ }^{4}$. In 1958, Apley and Naish reported a prevalence of $10.8 \%$ among British school children. Since then it has been studied all over the world, including Asian countries, and has been reported to occur in $8-12 \%$ of school aged children $^{5-9}$.

It is generally agreed that the complaint of pain made by children with RAP is genuine, and not simply social modelling, imitation of parental pain, or a means to avoid an unwanted experience (e.g. school phobia) $)^{10}$. The commonest presentation is periumbilical pain associated with autonomic and functional symptoms and other painful conditions $^{3,7,8}$. Thus, on initial presentation RAP may mimic any acute abdominal disorder, and may prompt extensive evaluation and unnecessary invasive investigation.

In their seminal study, Apley and Naish failed to identify an organic disease in $90 \%$ of children suffering from this problem $^{3}$ but recent studies have found organic pathologies in a higher percentage of affected children ${ }^{11-14}$. Nevertheless, the majority of children with this condition still have no identifiable organic disorders. Numerous organic disorders lead to abdominal pain; in most, the pathophysiology is related to infection (e.g. urinary tract infection), inflammation (e.g. Crohn disease) or distension or obstruction of a hollow viscus (e.g. obstructive uropathy) ${ }^{15}$. Helicobacter pylori (H. pylori) infection is one of the commonest bacterial infections in the world, and it has been suggested as a possible cause for childhood RAP, but the link between $H$. pylori infection and RAP is still controversial. Some studies have identified $H$. pylori as a possible aetiological factor for RAP and suggest its eradication in the management ${ }^{16-19}$ while other studies contradict this finding ${ }^{20-27}$.

Aetiology of RAP is complex in origin and does not lend itself to a single model of causation. The symptoms could not be explained by the traditional bio-medical model for aetiology which assumes that all conditions can be linearly reduced to a single aetiology. Therefore, a paradigm shift was clearly needed to explain abdominal pain in children with non-organic RAP when investigations such as haematology, biochemistry and endoscopy proved to be negative. The new "bio-psychosocial" model was introduced recently to look at this condition in an alternative way. It proposes that RAP results from simultaneous interactions between biological, socio-cultural and psychological factors. Biological factors such as genetic make up of a child interact with sociocultural factors and psychological factors, altering the physiology of the gastrointestinal tract and sensations giving rise to symptoms. Psychological and socio-cultural factors also alter the disease related behaviours such as health care consultation $^{28}$.

RAP is more common among children who have suffered stressful experiences ${ }^{3,7,29}$ and patients can sometimes date the onset of pain to a specific stressful event, such as change in school, birth of a sibling or separation of parents. The prevailing viewpoint is that the pathogenesis of the pain involves activation of brain gut axis resulting in gastrointestinal motility disturbances and visceral hypersensitivity $^{30}$. Adult and paediatric patients with functional dyspepsia often have gastrointestinal motor and electrical abnormalities and delayed transit ${ }^{31-39}$. Gastrointestinal myoelectrical and motility abnormalities are also reported in patients with irritable bowel syndrome ${ }^{40}$. Very few studies have investigated the association between gastrointestinal motility disturbances and functional RAP. These studies have demonstrated altered fasting gastrointestinal motility patterns ${ }^{41}$, abnormal electrical activity ${ }^{41}$ and impaired gastric accommodation ${ }^{42}$.

Without thorough knowledge on pathophysiology, childhood RAP is one of the most difficult conditions to manage. Only basic urine, stool and blood investigations are recommended to exclude organic causes in the diagnostic workup $^{10,15}$. Extensive radiographic evaluation and invasive investigations like endoscopy are rarely diagnostic or cost-effective ${ }^{43,44}$. The current recommendation in treating children with this condition includes support and empathy for the family, with reassurance that no serious disease is present ${ }^{45}$. With this approach, approximately $30 \%$ to $40 \%$ of children have resolution of their pain ${ }^{46}$. However, the remainder continues to exhibit symptoms and go on to be adults with functional gastrointestinal disorders, anxiety, or other somatic disorders ${ }^{47}$. Pharmaceutical treatments are commonly used in an effort to manage symptoms despite the lack of data supporting their efficacy.

This study has attempted to answer some of the questions related to epidemiology and pathophysiology of RAP in Sri Lankan children with emphasis on bio-psychosocial model of causation. This study was carried out in three phases. First phase was a school survey which assessed the epidemiology of RAP in Sri Lanka. 
Second phase was conducted to identify common organic and functional causes for RAP. Third step was carried out to investigate the gastrointestinal motility disturbances. This study protocol was approved by the Ethics Committee, Faculty of Medicine, University of Kelaniya.

Phase I - Epidemiological study to assess the prevalence of $R A P$

This phase of the study has been published in the Journal of Tropical Pediatrics ${ }^{48}$.

\section{Introduction}

Even though childhood recurrent abdominal pain is a worldwide problem, no epidemiological studies had been done in Sri Lanka to detect its prevalence. This school survey was conducted to assess the prevalence of RAP among school children in the Gampaha district of Sri Lanka, their clinical profile and the psychosocial factors associated with it.

\section{Methods}

In this school survey, four schools were randomly selected from the Gampaha district, and from each school, one class each was chosen randomly from academic years 1 to 9 . All students aged 5-15 years in the selected classes were included in the study. Written consent was obtained from parents or guardians. Pre-tested self administered parental questionnaires were distributed to those who consented and were returned by post. Reminders were sent twice to parents who failed to return the questionnaires. Information regarding demographic features, exposure to stressful life events, a history of RAP among first-degree relatives, associated symptoms and health care consultation was obtained. RAP was defined using Apley criteria ${ }^{3}$.

\section{Results and discussion}

Eight hundred and twenty five children were eligible for the study. Of them $810(98.2 \%)$ parents consented to participate. After two reminders, a total of $734(90.6 \%)$ questionnaires were returned. All of them were included in the analysis. [males $342(46.6 \%)$, mean age of 10.5 years (SD 2.7 years)]. The majority were Sinhalese $(95.0 \%)$ and Buddhists $(85.5 \%)$ reflecting the population demography of the district.
Prevalence of recurrent abdominal pain Seventy seven $(10.5 \%)$ children fulfilled the criteria for diagnosis of RAP. The prevalence of RAP among Sri Lankan children and adolescents in our study was similar to those previously reported. In 1958, Apley and Naish reported a prevalence of $10.8 \%$ among British school children, with girls $(12.3 \%)$ more commonly affected than boys $(9.5 \%)^{3}$. More recent studies in Western countries and in Asia have reported similar prevalence; e.g. $11.8 \%$ in British children ${ }^{9}$, $12 \%$ in Australian children ${ }^{6}, 11.5 \%$ among school children in Bangladesh ${ }^{7}$ and $10.2 \%$ in urban and rural school children in Malaysia (urban 8.2-9.6\%, rural $12.4 \%)^{5,8}$. Prevalence of RAP was highest in children between 10 and 11 years in our study which is in agreement with previous studies ${ }^{49}$. During analysis, 657 children without recurrent abdominal pain were considered as controls.

Clinical profile of the affected children

Abdominal pain was defined as mild when the child was able to walk about and carry out regular activities during episodes of pain and as moderate when the child needed to sit down. Pain was classified as severe if the child had to lie down during pain episodes ${ }^{50}$. If the child cried or screamed during pain episodes, it was considered very severe. The majority of the affected children had mild to moderate abdominal pain $(58.4 \%)$. In over half of the patients $(58.4 \%)$ pain was felt in the periumbilical region, and similar results have been reported from other countries ${ }^{3,6,7}$. The commonest symptoms associated with RAP that we found viz. headache (43\%), anorexia (35\%), lethargy $(23 \%)$, joint pain $(23 \%)$, nausea $(22 \%)$ and vomiting $(18 \%)$, were also similar to those reported in other studies ${ }^{3,7,8}$. We found an independent association between RAP and the presence of abdominal pain among first degree relatives $(55.8 \%$ vs. $44.2 \%, p<0.0001)$, a finding that has been reported previously ${ }^{3,7}$. This may be due to genetic or environmental vulnerability, and further studies should be directed at identifying a definite genetic predisposition.

Association between RAP and emotional stress RAP is well known to be commoner among children who are exposed to stressful situations in life $\mathrm{e}^{3,7,51,52}$ and we found similar results (Table 1). 
Table 1

Association between exposure to stressful life events and RAP

\begin{tabular}{|c|c|c|}
\hline Stressful event & $\operatorname{RAP} n(\%)$ & Controls $n(\%)$ \\
\hline Change in school & $15(19.7 \%)^{* *}$ & $54(8.2 \%)$ \\
\hline Frequent punishment in school & $04(5.2 \%)$ & $15(2.3 \%)$ \\
\hline Change in class or a favourite teacher & $07(9.2 \%)$ & $34(5.2 \%)$ \\
\hline Separation from best friend & $09(11.8 \%)$ & $39(5.9 \%)$ \\
\hline Failure in an examination & $03(3.9 \%)$ & $24(3.7 \%)$ \\
\hline Being bullied at school & $12(15.8 \%)^{* * *}$ & $32(4.9 \%)$ \\
\hline Change in address & $16(21.1 \%)^{* *}$ & $60(9.1 \%)$ \\
\hline Severe illness in a close family member & $19(25.0 \%)^{* * *}$ & $66(10.0 \%)$ \\
\hline Death of a close family member & $12(17.1 \%)$ & $87(13.2 \%)$ \\
\hline Loss of job by a parent & $07(9.2 \%)$ & $34(5.2 \%)$ \\
\hline Mother starting work & $05(6.6 \%)$ & $35(5.3 \%)$ \\
\hline Parent absent from home & $05(6.6 \%)$ & $17(2.6 \%)$ \\
\hline Divorce or separation of parents & $07(9.2 \%) * * *$ & $09(1.4 \%)$ \\
\hline Birth of a sibling & $05(6.6 \%)$ & $22(3.3 \%)$ \\
\hline Frequent domestic fights & $06(7.9 \%)^{*}$ & $18(2.7 \%)$ \\
\hline Frequent punishment by the parents & $07(9.2 \%)^{*}$ & $22(3.3 \%)$ \\
\hline Hospitalisation of the child for other illness & $07(9.2 \%)$ & $37(3.3 \%)$ \\
\hline Exposure to at least one stressful event & $22(28.6 \%) * * * *$ & $383(58.3 \%)$ \\
\hline
\end{tabular}

${ }^{*} p<0.05, * * p<0.01, * * * p<0.001, * * * * p<0.0001$

In agreement with previous studies in Malaysia, the stressful life events independently associated with RAP were being bullied at school $(p=0.02)$, severe illness in a close family member $(p=0.028)$ and divorce or separation of parents $(p=0.04)^{51,52}$.

\section{RAP and education}

Details regarding the child's academic performance were obtained from school records. The performance was categorised based on the performance in school end-of-term examinations during the year 2002. The top one third of the class (based on the ranking order of marks obtained) was considered as good, the middle one third as average and the bottom one third as poor. In contrast to the common belief that RAP is a disease of high achievers, this study failed to demonstrate significant associations between RAP and good academic performance $(36.4 \%$ vs. $33.6 \%$ in controls) nor participation in sports or other extracurricular activities (28.6\% vs. $24 \%)$. Similar results have been reported in previous studies ${ }^{2,3,6,53}$. In our study significantly higher numbers of children with RAP miss school compared to children without RAP (55.8\% vs. $24.4 \%)$. Rasul and Khan found that children with RAP miss an average of 8 days per year because of abdominal pain $^{7}$.

Health care consultation in children with recurrent abdominal pain

Fifty four $(70.1 \%)$ children with RAP had consulted a doctor during the previous 12 months for the abdominal pain. Of them, only $5(9 \%)$ had received in-patient care and the rest [49 (91\%)] were managed as out-patients. The health care consultation in our children is higher than previously reported [Hyams et al. (8\%), Huang et al. $(34.0 \%)$ and Boey and Goh $(45 \%$ and $48 \%)^{6,50,54,55}$. Availability of free health services and easy access to health care, probably have contributed to the higher prevalence of health care consultation in our study. Health care consultation was significantly higher when the child with RAP was the eldest in family ( $p=0.04)$, a good academic achiever $(p=0.02)$ and had pain associated with vomiting $(p=0.007)$. There was no significant association between the health care consultation and sex, younger age, pain severity, sleep interruption, family income, maternal employment, family size, school absenteeism, age of onset of RAP and frequency and duration of the pain episodes $(p>0.05)$. Previous studies have shown 
significant associations between health care consultation and age of onset, severity, frequency and duration of pain episodes, school absenteeism, sleep interruption and disruption of normal activity $^{50,54,55}$.

\section{Phase II - Laboratory based study to detect aetiology of RAP}

This phase of the study has been published in Journal of Paediatrics and Child Health. ${ }^{56}$

\section{Introduction}

Many diseases can cause abdominal pain, but, in clinical practice, the majority of children and adolescents presenting with this symptom have no evidence of organic disease. To rule out underlying organic disorders, children with RAP do not require an exhaustive series of diagnostic investigations. Excessive testing may increase parental anxiety and put the child through unnecessary stress. A correct diagnosis can be suspected following a good history and physical examination. Most researchers and clinicians suggest that investigation should be limited to a complete blood count, acute phase reactants, urine analysis and culture, and stool examination for parasitic infections ${ }^{15}$. Further diagnostic testing should be based on clinical suspicion of a particular organic disorder.

Recent studies have reported functional gastrointestinal disorders (FGD) in the majority of patients with RAP. For example, Walker et al. found FGD in $73 \%$ of patients with RAP using Rome II criteria for functional gastrointestinal disorders ${ }^{57}$ while Schurman et al. reported FGD in $84-89 \%{ }^{58}$. Unfortunately, some of the children with non-organic RAP (11-27\%) could not be classified into any FGD using Rome II criteria ${ }^{57-58}$.

To overcome drawbacks in Rome II criteria ${ }^{59}$, they were revised and modified in 2006, and Rome III criteria were developed ${ }^{60}$. Validity and reliability of Rome III criteria in diagnosing paediatric functional gastrointestinal diseases have yet to be studied. This is the first aetiological study on RAP among Sri Lankan children. Identifying common organic and functional causes for RAP in Sri Lankan children would be of a great advantage in the subsequent management.

\section{Method}

Fifty five children identified as having RAP during phase I were recruited after obtaining written consent from a parent. All patients were assessed by a consultant paediatrician and were screened for organic diseases using history, examination (including growth parameters), stool microscopy (for 3 consecutive days), urine microscopy and culture, full blood count, erythrocyte sedimentation rate (ESR) and abdominal radiograph. Investigations performed based on clinical judgment included serum amylase, renal and liver function tests, abdominal ultrasound, gastrointestinal endoscopy, barium contrast studies and intravenous urogram. The patients were followed up for 6 to 12 months. Children without clinical or laboratory evidence of organic diseases were classified into FGD using Rome II criteria ${ }^{59}$ and Rome III criteria ${ }^{60}$.

H. pylori status was assessed using a micro well based enzyme immune assay that detect $H$. pylori antigens in stools (FemtoLab H. pylori; Connex $\mathrm{GmbH}$, Germany). Subjects who had received antibiotics, acid suppression drugs or anti-H. pylori therapy during the previous 3 months, did not undergo $H$. pylori stool antigen test.

\section{Results and discussion}

Organic and functional causes for RAP

Out of 55 children screened, $13(23.6 \%)$ had identifiable aetiology for their symptoms [constipation (7), urinary tract infection (2), gastrooesophageal reflux disease (1), urinary calculi (1), antral gastritis and duodenitis (1) and intestinal amoebiasis (1)].

To date the only community-based study to detect the aetiology of RAP was Apley's field survey ${ }^{3}$ which reported organic diseases in $10 \%$ of affected children. Investigations were limited during that period and recent advances in diagnostic facilities have probably contributed to the higher proportion of organic diseases seen in our patients with RAP. Prevalence of organic diseases in our study was comparable to that reported by Dutta et al. (26\%) in children with RAP attending a paediatric outpatient clinic in India ${ }^{11}$ and Alfven $(25 \%)$ in abdominal pain clinic in Sweden ${ }^{29}$. Some previous studies have reported higher percentage of organic diseases in children with RAP [e.g. Balani et al. $(74.2 \%)^{12}$, Buch et al. $(82.4 \%)^{13}$, Stordal et al. $\left.(45 \%)^{14}\right]$. Inclusion of very young children may have accounted for the high percentage of organic diseases in these studies. Similar to our study, Stordal et al. also reported constipation as a leading cause of $\mathrm{RAP}^{14}$, while several Indian studies have recognized intestinal parasitic infections, including giardiasis, as the leading cause for RAP ${ }^{11-13}$. Other diseases commonly recognized were urinary tract infection, Helicobacter pylori infection and lactose intolerance ${ }^{11-14}$.

Until a decade ago 'functional gastrointestinal disorder' was a label used for conditions with uncertain aetiology, and when Rome II criteria 
were defined to diagnose FGD, they became an important positive diagnosis ${ }^{59}$. We were able to classify 33 children with RAP (79\% patients with non-organic RAP, $60 \%$ of total) as having FGD using paediatric Rome II criteria (Table 2) which is comparable to results obtained by Walker et al. and Schurman et al. $(73-89 \%)^{57,58}$. Functional abdominal pain was the leading FGD in our children (Table 2). In the study done by Walker et al., the majority of children had irritable bowel syndrome $(44.9 \%)^{57}$. Schurman et al. reported functional dyspepsia as the commonest functional $\operatorname{aetiolog} \mathrm{y}^{58}$.

Table 2

Prevalence of abdominal pain related functional gastrointestinal diseases in children with RAP

\begin{tabular}{|l|c|c|}
\hline \multicolumn{1}{|c|}{ FGD } & Rome II criteria $\boldsymbol{n ~ ( \% ) ~}$ & Rome III criteria $\boldsymbol{n}(\mathbf{\%})$ \\
\hline Functional abdominal pain & $13(31 \%)$ & $19(45.2 \%)$ \\
\hline Functional dyspepsia & $9(21.4 \%)$ & $9(21.4 \%)$ \\
\hline Irritable bowel syndrome & $9(21.4 \%)$ & $9(21.4 \%)$ \\
\hline Abdominal migraine & $1(2.4 \%)$ & $1(2.4 \%)$ \\
\hline Aerophagia & $1(2.4 \%)$ & $\mathbf{3 9}(\mathbf{9 2 . 9 \% )}$ \\
\hline FGD total & $\mathbf{3 3 ( 7 8 . 6 \% )}$ & $\mathbf{3 ( 7 . 1 \% )}$ \\
\hline Non specific abdominal pain & $\mathbf{9 ( 2 1 . 4 \% )}$ & \\
\hline
\end{tabular}

When Rome III criteria were used, the percentage of children with functional abdominal pain increased to 39 (93\% of non-organic RAP, $71 \%$ of total) (Table 2). Using Rome III criteria, only 3 patients could not be classified into any category. As there are no studies in children with RAP using Rome III criteria we could not make a comparison.

Association between $H$. pylori infection and RAP Twenty healthy controls [10 (50\%) males, age 5-15 years, mean 9 years, SD 2.7 years] and 39 patients with functional RAP [16 (41\%) males, mean age 7.9 years, SD 3 years] underwent stool antigen test for H. pylori. Two (5.1\%) patients and one (5\%) control tested positive $(p>0.05)$.

The prevalence of $H$. pylori infection in our study is comparable to that reported among Sri Lankan school children previously $(6.5 \%$ by detection of faecal antigen test $)^{61}$. In agreement with our results, several previous studies also failed to demonstrate an association between $H$. pylori infection and childhood $\mathrm{RAP}^{20-27}$. Treatment trial done by Wewer et al. also failed to demonstrate an association between these two conditions ${ }^{26}$. Collectively analysing six studies done in North America, Europe and Australia, Gold reported a $H$. pylori prevalence of $5-18 \%$ in children with abdominal pain and $5-29 \%$ in children without abdominal pain indicating a lack of association between the two conditions ${ }^{25}$. However, some researchers have demonstrated an association between $H$. pylori and childhood RAP, including resolution of symptoms following eradication of infection ${ }^{16-19}$. Several of these studies included very young children and since the subjective feeling of abdominal pain is difficult to assess in younger children, the reliability of the diagnosis of RAP was in question ${ }^{17,18}$. Many of these treatment trials were not blinded or randomised ${ }^{16,18}$, used different tests to confirm $H$. pylori eradication ${ }^{18}$, had no validated symptom scores $^{18,19}$ or used a small sample $^{16}$. This has reduced the validity of their conclusions.

Pain characteristics and associated symptoms in organic and functional RAP

The concept of recognizing "red flags" that suggest organic disease has long been a tradition in management of childhood abdominal pain. Contrary to common beliefs and recommendations ${ }^{10}$, the majority of pain characteristics and associated symptoms, including many alarm symptoms, were not commoner in patients with an organic aetiology compared to those with functional RAP. The symptom associated with organic aetiology in our study was presence of vomiting and nocturnal pain (Table 3 ). There has been no firm evidence to state that the nature of the abdominal pain or the presence of associated symptoms can discriminate between functional and organic disorders ${ }^{45}$.

In our study, a higher percentage of patients with functional RAP had a family history of RAP $(42.9 \%)$ compared to those with organic RAP (23.2\%), although the difference was not significant. We found no difference in health care consultation between organic $(76.9 \%)$ and functional RAP (73.8\%). Similar to the study done by Walker and Green ${ }^{62}$, the present study found no difference in exposure to stressful life events in patients with organic and functional RAP (69.2\% vs. $64.3 \%)$. 
Table 3

Comparison of symptoms in patients with organic and functional RAP

\begin{tabular}{|l|c|c|}
\hline & Organic RAP $(\boldsymbol{n}=\mathbf{1 3})$ & Functional RAP (n=42) \\
\hline Severity & & $11(26.2 \%)$ \\
Mild & $2(15.4 \%)$ & $8(19.1 \%)$ \\
Moderate & $3(23.0 \%)$ & $14(33.3 \%)$ \\
Severe & $4(30.8 \%)$ & $9(21.4 \%)$ \\
Very severe & $4(30.8 \%)$ & \\
\hline Localization & & $28(66.6 \%)$ \\
Periumbilical area & $10(76.9 \%)$ & $8(19.1 \%)$ \\
Epigastric area & $2(15.4 \%)$ & $4(9.5 \%)$ \\
Other & $1(7.7 \%)$ & $2(4.8 \%)$ \\
Undetermined & 0 & $2(4.8 \%)$ \\
\hline Type of pain & & $19(45.2 \%)$ \\
Burning & 0 & $15(35.7 \%)$ \\
Colicky/cramp like & $7(53.8 \%)$ & $6(14.3 \%)$ \\
Continuous & $3(23.0 \%)$ & \\
Undetermined & $3(23.0 \%)$ & $19(45.2 \%)$ \\
\hline Associated symptoms ${ }^{\dagger}$ & & $10(23.8 \%)$ \\
Headache & $4(30.8 \%)$ & $10(23.8 \%)$ \\
Anorexia & $7(53.8 \%)$ & $10(23.8 \%)$ \\
Lethargy & $3(23.0 \%)$ & $6(14.3 \%)$ \\
Weight loss & $5(38.5 \%)$ & $7(16.7 \%)$ \\
Dysuria & $4(30.8 \%)$ & $5(11.9 \%)$ \\
Joint pain & $3(23.0 \%)$ & $3(7.1 \%)$ \\
Nausea & $4(30.8 \%)$ & $1(2.4 \%)$ \\
Vomiting & $5(38.5 \%)$ & $3(7.1 \%)$ \\
Diarrhoea & $2(15.4 \%)$ & \\
\hline Nocturnal pain & $4(30.8 \%)^{* *}$ & \\
\hline OR=0.12 $0.01(F i s h e r$ & \\
\hline
\end{tabular}

$* O R=0.12, p=0.01$ (Fisher exact test), $* * O R=4.99, p=0.03$ (Fisher exact test)

${ }^{\dagger}$ some patients had more than one symptom

Phase III - Assessment of gastrointestinal motility This phase of the study was published in the Journal of Gastroenterology and Hepatology. ${ }^{63}$

\section{Introduction}

There have been only limited studies to detect the gastrointestinal motility abnormalities in children with RAP. Pineiro-Carrero et al. showed that the children with RAP had more migrating motor complexes compared to healthy children, but these were shorter in duration and showed impaired propagation down the intestine ${ }^{41}$. These patients also had high-pressure duodenal contractions that were associated with abdominal pain. Olafsdottir et al. showed an impairment in accommodation of the proximal stomach following a liquid meal in children with RAP compared to healthy children ${ }^{42}$. This study failed to show a significant relationship between emptying of the distal stomach and RAP.

We evaluated gastric myoelectrical activity, gastric emptying rate, antral motility and intestinal transit time in children with recurrent abdominal pain syndrome. Understanding the gastrointestinal motility abnormalities in such patients will widen the knowledge of the pathophysiology of the condition and potentially improve the management of the affected children.

\section{Methods}

Selection of study subjects

Forty two children and adolescents with functional RAP and 20 healthy controls [10 (50\%) males, mean 9 years, SD 2.7 years] were recruited from same area, after obtaining parental consent.

Children who had previous abdominal surgery, children with fever, common cold, respiratory tract symptoms, gastroenteritis and any other systemic infection during the previous month, children who received prokinetic drugs or any other drugs that can alter gastrointestinal motility during the previous month and children who received antibiotics during the previous month were excluded from the study.

Electrogastrography (EGG), gastric emptying ultrasound and oro-caecal transit time measurement were performed on three consecutive days at approximately 9.00am. 
EGG recording

Electrogastrography or EGG is the gastric equivalent of ECG in the heart and EEG in the brain. It is the cutaneous measurement of electrical activity of gastric smooth muscle. EGG is capable of assessing rate and rhythm of slow waves. Spikes are represented as increase in amplitude ${ }^{64}$. In this study, EGG was recorded using a portable EGG recorder (Digitrapper EGG, Synetics Medical, Sweden) after an overnight fast, 1 hour before and 1 hour after a standard test meal (egg sandwich) ${ }^{64}$.

Measurement of gastric emptying and antral motility

Gastric emptying rate and antral motility were evaluated using a previously reported ultrasound method (SD-550, Aloka, Japan with $3.5 \mathrm{MHz}$ and $5 \mathrm{MHz}$ curve transducers) ${ }^{36}$. The ultrasound probe was positioned vertically to permit simultaneous visualization of the antrum, left lobe of liver, superior mesenteric artery, and abdominal aorta. The antral cross sectional area was measured tracing the mucosal side of the wall. For assessment of gastric emptying rate, antral area was measured at $1 \mathrm{~min}$ and $15 \mathrm{~min}$ after drinking the test meal $(200 \mathrm{~mL}$ of chicken broth). For assessment of antral motility, it was measured during contractions and relaxations.

Gastric emptying and antral motility parameters calculated were:

- Gastric emptying $=$ [Antral area at $1 \mathrm{~min}-$ Antral area at $15 \mathrm{~min}] /$ Antral area at $1 \mathrm{~min} x$ 100

- $\quad$ Frequency of antral contractions $=$ Number of contractions per $3 \mathrm{~min}$

- Amplitude of contractions $=[$ Antral area at relaxation - Antral area at contraction]/Antral area at relaxation $\mathrm{x} 100$

- Motility index $=$ [Amplitude of antral contraction $x$ Frequency of contraction]/100

Measurement of oro-caecal transit time

Oro-caecal transit time was measured by lactulose breath hydrogen test ${ }^{65}$. Analysis of breath hydrogen concentration is a simple and accurate method to study small bowel transit. Comparative studies with radioisotopes and radio-labelled markers have clearly indicated that the rise in breath hydrogen concentration coincides with the entry of nonabsorbable carbohydrate residues into the caecum $^{66}$. Lactulose was utilized as the test substance in the present study because this disaccharide is not hydrolyzed by the enzymes in small intestine and therefore, small bowel absorption is negligible. However, colonic bacteria are able to ferment this sugar liberating $\mathrm{H}_{2}$ in the process. Since the stomach begins to empty substances almost immediately following their ingestion, the time that elapses between the ingestion of lactulose and the first significant increase in $\mathrm{H}_{2}$ excretion is an approximate measure of the small intestinal transit time ${ }^{65}$

During this study, end expiratory breath hydrogen levels were measured during fasting period and every $15 \mathrm{~min}$ after ingestion of lactulose $(0.25 \mathrm{~g} / \mathrm{kg}$ 1 in $10 \%$ solution up to a maximum of $10 \mathrm{~g}$ ), for 240min using a portable breath hydrogen analyzer (Micro $\mathrm{H}_{2}$ Monitor, Fischer ANalysen Instrumente $\mathrm{GmbH}$, Leipzig, Germany). Oro-caecal transit time was calculated as the time elapsed from completion of drinking the lactulose solution to a rise in breath hydrogen level more than 10ppm above fasting level, sustained for at least 2 consecutive $15 \mathrm{~min}$ intervals ${ }^{65}$.

\section{Results and discussion}

Gastric emptying and antral motility in patients and controls

This study has demonstrated abnormalities in main gastric motility parameters, gastric emptying rate, amplitude of antral contractions and antral motility index in children with RAP for the first time (Table 4). Only one previous study has assessed gastric motility in children with RAP and it has demonstrated a significant impairment of adaptive relaxation of the proximal stomach in affected children $^{42}$. Cucchiara et al. showed a significantly prolonged gastric emptying time in children with functional dyspepsia ${ }^{31}$. In another study, a significantly higher percentage of children with functional dyspepsia had delayed gastric emptying of a solid/liquid meal compared to controls ${ }^{34}$.

Table 4

Comparison of gastric motility parameters in patients and controls

\begin{tabular}{|l|c|c|c|c|c|}
\hline & \multicolumn{2}{|c|}{ Functional RAP } & \multicolumn{2}{c|}{ Healthy controls } & \multirow{2}{*}{$\boldsymbol{p}$ value } \\
\hline & Mean & SD & Mean & SD & \\
\hline Fasting antral area $\left(\mathrm{cm}^{\mathbf{2}}\right)$ & 0.81 & 1.0 & 0.61 & 1.0 & 0.159 \\
\hline Gastric emptying (\%) & 46.49 & 19.2 & 66.17 & 16.5 & $<0.001$ \\
\hline Amplitude of antral contractions (\%) & 74.35 & 17.9 & 89.01 & 10.1 & $<0.001$ \\
\hline Frequency of antral contractions (3min) & 8.76 & 1.8 & 9.25 & 0.8 & 0.251 \\
\hline Antral motility index & 6.51 & 2.0 & 8.26 & 1.3 & $<0.001$ \\
\hline
\end{tabular}

Mann-Whitney U-test 
The delayed liquid gastric emptying we observed in our patients could be due to impairment in antral motility. Our results are in agreement with those of Kusunoki et al. who demonstrated antral hypomotility in adults with functional dyspepsia ${ }^{36}$. Furthermore, gastric emptying had a negative correlation with the score obtained for symptoms $(r=-63, \quad p<0.0001)$. Similarly, a significant correlation between the postprandial antral dilatation and the total symptom score was demonstrated in a previous study ${ }^{37}$.

EGG parameters in patients and controls The EGG parameters of both groups, during fasting and post-prandial periods are shown in Table 5. In this study, the instability co-efficient of dominant frequency which is a measurement of instability of dominant frequency, was significantly increased in children with RAP and correlated with the severity of abdominal pain $(\mathrm{r}=0.26, \mathrm{p}=0.04)$.

Table 5

Comparison of EGG parameters between children with functional RAP and healthy controls

\begin{tabular}{|l|c|c|c|c|c|c|c|c|}
\hline & \multicolumn{3}{|c|}{ Functional RAP (n=42) } & \multicolumn{3}{c|}{ Healthy children (n=20) } \\
\hline & \multicolumn{2}{|c|}{ Fasting period } & \multicolumn{2}{c|}{$\begin{array}{c}\text { Postprandial } \\
\text { period }\end{array}$} & \multicolumn{2}{c|}{ Fasting period } & \multicolumn{2}{c|}{$\begin{array}{c}\text { Postprandial } \\
\text { period }\end{array}$} \\
\hline & Mean & SD & Mean & SD & Mean & SD & Mean & SD \\
\hline Dominant frequency & 2.9 & 0.9 & 3.1 & 0.6 & 3.0 & 0.31 & 3.2 & 0.5 \\
\hline Dominant power & 750 & 1165 & 2726.3 & 2927 & 883.7 & 1689 & 3246.9 & 2823 \\
\hline \% of normal waves & 85.6 & 14.7 & 89.6 & 8.4 & 90.7 & 12.1 & 92.5 & 10.0 \\
\hline \% of tachygastria & 9.6 & 12.8 & 5.8 & 5.7 & 4.8 & 9.1 & 4.6 & 7.7 \\
\hline \% of bradygastria & 4.4 & 4.7 & 4.5 & 6.6 & 4.5 & 7.7 & 3.5 & 6.1 \\
\hline DFIC & 35.1 & 21.1 & $27.8 *$ & 12.3 & 27.7 & 17.8 & 18.3 & 12.8 \\
\hline DPIC & 71.7 & 22.0 & 83.0 & 10.8 & 69.3 & 20.7 & 76.4 & 33.8 \\
\hline Post/pre EGG power ratio & - & - & 8.9 & 10.8 & - & - & 11.4 & 12.4 \\
\hline
\end{tabular}

$p=0.008$, Mann-Whitney U-test

DFIC $=$ dominant frequency instability co-efficient, DPIC $=$ dominant power instability co-efficient

EGG has not been done in children with RAP, EGG abnormalities were reported previously in children with functional dyspepsia. Cucchiara et al. reported a significant increase in the arrhythmic index in children with functional dyspepsia during both fasting and post-prandial periods and the arrhythmic episodes coincided with periods of dyspeptic symptoms in $50 \%$ of patients ${ }^{31}$. In the study done by Chen et al., children with functional dyspepsia had a significantly lower percentage of $2-4 \mathrm{cpm}$ slow waves and significantly higher instability of the dominant frequency during both the fasting and fed state $^{67}$. In addition, the postprandial increase in dominant power was inversely correlated with the total symptom score. Riezzo et al. reported a significant increase in tachygastria, a higher instability of gastric power and a lower post/pre-prandial ratio in children with dyspeptic symptoms compared to healthy controls ${ }^{34}$. In the study done by Friesen et al., 50\% of patients with functional dyspepsia had an abnormal EGG, and patients with an abnormal EGG had a higher mean post-prandial abdominal pain severity score ${ }^{68}$.

Oro-caecal transit time in patients with RAP and healthy children

We have found significantly prolonged oro-caecal transit times in patients with RAP (mean 93.3min, SD $30.6 \mathrm{~min}$ ) compared to controls (mean $68.4 \mathrm{~min}$, $\mathrm{SD} 17 \mathrm{~min})(p=0.004)$.
Small intestinal motor abnormalities are reported in patients with RAP and functional dyspepsia. Chitkara et al. studied gastrointestinal transit in children with upper abdominal pain and discomfort using scintigraphy ${ }^{39}$ and in that study, small bowel transit was slow in $40 \%$ of the children with functional dyspepsia. They also demonstrated a significant association between abdominal bloating and slow small intestinal transit, but we failed to find such a correlation with abdominal pain. Waldron et al. have reported prolonged oro-caecal transit time in adult patients with functional dyspepsia $^{69}$. Lu et al. reported delayed small intestinal transit in adults with constipation predominant irritable bowel syndrome while it was accelerated in those with diarrhoea predominant irritable bowel syndrome ${ }^{70}$.

Pathogenesis of abnormal gastrointestinal motility in $R A P$

The pathogenesis of abnormal gastrointestinal motility in patients with recurrent abdominal pain is not fully understood. Emotional stress is suggested as a possible cause for abnormal gastrointestinal motility. Stress-mediated changes in gastrointestinal motility are known to occur in healthy subjects as well as in patients with functional bowel disorders like irritable bowel syndrome $^{71}$. Some studies have also shown that patients with functional bowel diseases have greater reactivity to stress than healthy subjects ${ }^{71}$. 
Psychological factors are likely to influence gut function via autonomic efferent neural pathways. Studies assessing autonomic functions in children with RAP have given contradictory results. One study has shown autonomic abnormalities in children with functional abdominal pain ${ }^{72}$, while another study failed to show such abnormalities ${ }^{73}$.

\section{The value of gastrointestinal motility assessment in $R A P$}

The therapeutic value of drugs that normalize gastrointestinal motility is not well documented in children. According to Duan et al., scores obtained for dyspeptic symptoms are significantly higher in patients with delayed gastric emptying than in those with normal emptying. Administration of a prokinetic drug (domperidone) not only improved gastric emptying time, but also relieved symptoms in these patients, while placebo had no such effect. In contrast, domperidone had no significant effect on both gastric emptying and symptoms in patients with normal gastric emptying ${ }^{74}$. 5-HT receptor antagonists such as Tegaserod, in addition to decreasing visceral hypersensitivity, have been shown to accelerate gastrointestinal transit in patients with constipation predominant irritable bowel syndrome ${ }^{75}$.

\section{Conclusions}

In our study, the epidemiology of recurrent abdominal pain in Sri Lanka is similar to that of other countries, affecting nearly $10 \%$ of school children and adolescents. In agreement with previous studies the majority have mild to moderate central abdominal pain associated with other painful conditions like headache and limb pain, and autonomic symptoms such as lethargy, nausea and vomiting. Recurrent abdominal pain has significant associations with exposure to recent stressful life events and a history of recurrent abdominal pain among first degree relatives. No associations were observed between this syndrome and socio-economic status or school performance. Approximately $70 \%$ of patients had consulted a doctor for their symptoms in contrast to previous studies in which the majority were non-consulters.

We found organic pathology only in less than $25 \%$ of patients with RAP. Functional gastrointestinal diseases were present in over two third (75\%). The commonest functional gastrointestinal disorder observed in this study was functional abdominal pain, followed by irritable bowel syndrome and functional dyspepsia. Classification of non-organic RAP into the appropriate functional bowel disorder helps to let the child and the parents know that the symptoms they are feeling are real but not dangerous or life threatening, and also helps to direct the treatment appropriately. Once the diagnosis is made, a simple explanation of the condition and reassurance is usually enough to alleviate anxiety in the child and the family. In agreement with previous studies, we did not find an association between Helicobacter pylori infection and RAP.

For the first time, we have demonstrated impaired gastric myoelectrical activity, delayed gastric emptying, impaired antral motility and prolonged oro-caecal transit in patients with recurrent abdominal pain. Our results indicate the importance of gastrointestinal motility disturbances in the pathogenesis of non-organic recurrent abdominal pain in children and adolescents. Cutaneous electrogastrography, gastric emptying ultrasound and lactulose breath hydrogen test are safe, noninvasive techniques, which are helpful in identifying altered gastrointestinal function in these children. Such information may be quite useful in understanding the pathophysiology of the condition and in directing an effective management plan. It remains to be established whether drugs that normalize the gastrointestinal motor activity result in improvement in symptoms. Future studies should be directed at establishing a possible therapeutic effect of prokinetic drugs in the management of this condition.

I believe that this study has broadened the understanding of epidemiology and aetiology of childhood recurrent abdominal pain in Sri Lanka and has thrown some light upon the future management strategies. I hope the findings of this study will help improve the management of children with this complex and obscure disease condition.

\section{Acknowledgements}

I wish to thank Prof. H. Janaka de Silva and Prof. Harendra de Silva, my supervisors, for their intellectual and personal support, Professor Ken Haruma and associate professor H. Kusunoki, for teaching me gastric emptying ultrasound, Mrs. Janeshwari Liyanage and Mrs. Ranjani Subasinghe for their technical assistance and the National Science Foundation, Sri Lanka and University of Kelaniya for funding this research project. My special gratitude goes to Dr. Udaya Ranawaka, for his guidance in preparation of this oration.

I am also deeply grateful to my colleagues in the Department of Physiology, the staff of ward 23, Teaching Hospital, Ragama and all the children who participated in this study and their parents, for their help and co-operation. 


\section{References}

1. Still GF. Common disorders and diseases of childhood. London: Oxford University Press 1909.

2. O'Donnell B. Abdominal pain in children. Blackwell Scientific Publications, Worcester, 1985: 106-13.

3. Apley J, Naish N. Recurrent abdominal pain: A field survey of 1000 school children. Arch Dis Child 1958; 33(168): 165-70.

4. Roth-Isigkeit A, Thyen U, Raspe HH, Stoven H, Schmucker P. Reports of pain among German children and adolescents: an epidemiological study. Acta Paediatr 2004; 93(2): 258-63.

5. Boey C, Yap S, Goh KL. The prevalence of recurrent abdominal pain in 11- to 16-year-old Malaysian schoolchildren. J Paediatr Child Health 2000; 36(2): 114-6.

6. Huang RC, Plamer LJ, Forbes DA. Prevalence and pattern of childhood abdominal pain in an Australian general practice. J Paediatr Child Health 2000; 36(4): 349-53.

7. Rasul $\mathrm{CH}$, Khan MAD. Recurrent abdominal pain in school children in Bangladesh. Journal of the Ceylon College of Physicians 2000; 33: $110-4$.

8. Boey CC, Goh KL. Predictors of recurrent abdominal pain among 9 to 15 -year-old urban school children in Malaysia. Acta Paediatr 2001; 90(3): 353-5.

9. Ramchandani PG, Hotopf M, Sandhu B, Stein A. The epidemiology of recurrent abdominal pain from 2 to 6 years of age: results of a large, population-based study. Pediatrics 2005; 116(1): 46-50.

10. Boyle JT. Recurrent abdominal pain: An update. Pediatr Rev 1997; 18(9): 310-20.

11. Dutta S, Mehta M, Verma IC. Recurrent abdominal pain in Indian children and its relation with school and family environment. Indian Pediatr 1999; 36(9): 917-20.

12. Balani B, Patwari AK, Bajaj P, Diwan N, Anand VK. Recurrent abdominal pain -A reappraisal. Indian Pediatr 2000; 37(8): 87681.
13. Buch NA, Ahmad SM, Ahmad SZ, Ali SW, Charoo BA, Hassan MU. Recurrent abdominal pain in children. Indian Pediatr 2002; 39(9):830-4.

14. Stordal K, Nygaard EA, Bentsen B. Organic abnormalities in recurrent abdominal pain in children. Acta Paediatr 2001; 90(6): 638-42.

15. Pearl RH, Irish MS, Caty MG, Glick PL. The approach to common abdominal diagnosis in infants and children. Part II. Pediatr Clin North Am 1998; 45(6): 1287-326,vii.

16. Frank F, Stricker T, Stallmach T, Braegger CP. Helicobacter pylori infection in recurrent abdominal pain. J Pediatr Gastroenterol Nutr 2000; 31(4): 424-7.

17. Kimia A, Zahavi H, Shaprio R, Rosenbach Y, Hirsh A, Drudz $T$, et al. The role of Helicobacter pylori and gastritis in children with recurrent abdominal pain. Isr Med Assoc $J$ 2000; 2(2): 126-8.

18. Ozen H, Dinler G, Akyon Y, Kocak N, Yuce A, Gurakan F. Helicobacter pylori infection and recurrent abdominal pain in Turkish children. Helicobacter 2001; 6(3): 234-8.

19. Das BK, Kakkar S, Dixit VK, Kumar M, Nath G, Mishra OP. Helicobacter pylori infection and recurrent abdominal pain in children. $J$ Trop Pediatr 2003; 49(4): 250-2.

20. Macarthur C, Saunders N, Feldman W. Helicobacter pylori, gastroduodenal disease, and recurrent abdominal pain in children. JAMA 1995; 273(9): 729-34.

21. Hardikar W, Feekery C, Smith A, Oberklaid F, Grimwood K. Helicobacter pylori and recurrent abdominal pain. $J$ Pediatr Gastroenterol Nutr 1996; 22(2): 148-52.

22. Bansal D, Patwari AK, Malhotra VL, Malhotra V, Anand VK. Helicobacter pylori infection in recurrent abdominal pain. Indian Pediatr 1998; 35(4): 329-35.

23. Kansu A, Kalayci AG, Ulukol B, Dodanci T, Gyrgyn N. Importance of Helicobacter pylori in the etiology of chronic abdominal pain. Turk J Gastroenterol 1999; 10(1): 24-6.

24. Macarthur C, Saunders N, Feldman W, Ipp M, Winders-Lee P, Roberts S, et al. Helicobacter pylori and childhood recurrent abdominal pain: Community based case-control study. BMJ 1999; 319(7213): 822-3. 
25. Gold BD, Colletti RB, Abbott M, Czinn SJ, Elitsur Y, Hassall E, et al. Helicobacter pylori infection in children: recommendation for diagnosis and treatment. $J$ Pediatr Gastroenterol Nutr 2000; 31(5): 490-7.

26. Wewer V, Andersen LP, Paerregaard A, Gernow A, Hansen JP, Matzen P, et al. Treatment of Helicobacter pylori in children with recurrent abdominal pain. Helicobacter 2001; 6(3): 244-8.

27. Bode G, Brenner H, Adler G, Rothenbacher D. Recurrent abdominal pain in children: evidence from a population-based study that social and familial factors play a major role but not Helicobacter pylori infection. $J$ Psychosom Res 2003; 54(5): 417-21.

28. Drossman DA. Presidential address: Gastrointestinal illness and the biopsychosocial model. J Clin Gastroenterol 1996; 22(4): 252-4.

29. Alfven G. One hundred cases of recurrent abdominal pain in children: diagnostic procedures and criteria for a psychosomatic diagnosis. Acta Paediatr 2003; 92(1): 43-9.

30. Delvaux M. Role of visceral sensitivity in the pathophysiology of irritable bowel syndrome. Gut 2002; 51 (Suppl 1): i 67-71.

31. Cucchiara S, Riezzo G, Minella R, Pezzolla F, Giorgio I, Auricchio S. Electrogastrography in non-ulcer dyspepsia. Arch Dis Child 1992; 67 (5): 613-7.

32. Pfaffenbach B, Adamek RJ, Bartholamaus C, Wegener M. Gastric dysrhythmias and delayed gastric emptying in patients with functional dyspepsia. Dig Dis Sci 1997; 42(10): 2094-9.

33. Riezzo G, Chiloiro M, Guerra V, Borrelli O, Salvia G, Cucchiara S. Comparison of gastric electrical activity and gastric emptying in healthy and dyspeptic children. Dig Dis $\mathrm{Sci}$ 2000; 45(3): 517- 24.

34. Riezzo G, Chiloiro M, Russo F, Clemente C, Di Matteo G, Guerra V, et al. Gastric electrical activity and gastrointestinal hormones in dyspeptic patients. Digestion 2001; 63(1): 20 9.

35. Lin X, Chen JZ. Abnormal gastric slow waves in patients with functional dyspepsia assessed by multichannel eletrogastrography. $A m ~ J$ Physiol Gastrointest Liver Physiol 2001; 280(6): G1370-5.
36. Kusunoki H, Haruma K, Hata J, Tani H, Okamoto E, Sumii K, et al. Real time ultrasonographic assessment of antroduodenal motility after ingestion of solid and liquid meals by patients with functional dyspepsia. $J$ Gastroenterol Hepatol 2000; 15(9): 1022-7.

37. Hausken T, Berstad A. Wide gastric antrum in patients with non-ulcer dyspepsia. Effect of cisapride. Scand J Gastroenterol 1992; 27(5): 427-32.

38. Gilja OH, Hausken T, Wilhelmsen I, Berstad A. Impaired accommodation of proximal stomach to a meal in functional dyspepsia. Dig Dis Sci 1996; 41(4): 689-96.

39. Chitkara DK, Delgado-Aros S, Bredenoord AJ, Cremonni F, El-Youssef M, Freese D, et al. Functional dyspepsia, upper gastrointestinal symptoms, and transit in children. $J$ Pediatr 2003; 143 (5): 609-13

40. Portincasa P, Moschetta A, Baldassarre G, Altomare DF, Palasciano G. Pan-enteric dysmotility, impaired quality of life and alexithymia in a large group of patients meeting ROME II criteria for irritable bowel syndrome. World J Gastroenterol 2003; 9(10): 2293-9.

41. Pineiro-Carrero VM, Andres JM, Davis RH, Mathias JR. Abnormal gastroduodenal motility in children and adolescents with recurrent functional abdominal pain. J Pediatr 1988; 113(5): 820-5.

42. Olafsdottir E, Gilja OH, Aslaksen A, Berstad A, Fluge G. Impaired accommodation of the proximal stomach in children with recurrent abdominal pain. J Pediatr Gastroenterol Nutr 2000; 30(2): 157-63.

43. Shannon A, Martin DJ, Feldman W. Ultrasonographic studies in the management of recurrent abdominal pain. Pediatrics 1990; 86(1): $35-8$.

44. Boey CC, Goh KL, Hassall E, Maqiod M. Endoscopy in children with recurrent abdominal pain. Gastrointest Endosc 2001; 53 (1): 142-3.

45. Di Lorenzo C, Colletti RB, Lehmann HP, Boyle JT, Gerson WT, Hyams JS, et al.; American Academy of Pediatrics Subcommittee on Chronic Abdominal Pain; NASPGHAN Committee on Abdominal Pain. Chronic abdominal pain in children: a clinical report of the American Academy of Pediatrics 
and the North American Society for Pediatric Gastroenterology, Hepatology and Nutrition. $J$ Pediatr Gastroenterol Nutr 2005; 40(3):245-8.

46. Christensen MF, Mortensen O. Long-term prognosis in children with recurrent abdominal pain. Arch Dis Child 1975; 50 (2): 110-4.

47. Campo JV, Di Lorenzo C, Chiappetta L, Bridge J, Colborn DK, Gartner J, et al. Adult outcomes of pediatric recurrent abdominal pain: do they just grow out of it? Pediatrics 2001; 108 (1): E1.

48. Devanarayana NM, de Silva DG, de Silva HJ. Recurrent abdominal pain syndrome in a cohort of Sri Lankan children and adolescents: $J$ Trop Pediatr 2008 ; 54(3) : 178-83.

49. Wyllie R, Kay M. Causes of recurrent abdominal pain. Clin Pediatr (Phila) 1993; 32(6): 369-71.

50. Boey CCM, Goh KL. Predictors of health care consultation for recurrent abdominal pain among urban school children in Malaysia. $J$ Gastroenterol Hepatol 2001; 16(2): 154-9.

51. Boey CCM, Goh KL. Stressful life events and recurrent abdominal pain in children in a rural district in Malaysia. Eur $J$ Gastroenterol Hepatol 2001; 13(4): 401-4.

52. Boey CCM, Goh KL. The significance of lifeevents as contributing factors in childhood recurrent abdominal pain in an urban community in Malaysia. $J$ Psychosom Res 2001; 51(4): 559-62

53. Boey CCM, Omar A, Phillipa JA. Correlation among academic performance, recurrent abdominal pain and other factors in year-6 urban primary-school children in Malaysia. $J$ Paediatr Child Health 2003; 39(5): 352-7

54. Boey CCM, Goh KL. Recurrent abdominal pain and consulting behaviour among children in a rural community in Malaysia. Dig Liver Dis 2001; 33(2): 140-4.

55. Hyams JS, Burke G, Davis PM, Rzepski B, Anbrulons PA. Abdominal pain and irritable bowel syndrome in adolescents: a community based study. J Pediatr 1996; 129(2): 220-6.

56. Devanarayana NM, de Silva DG, de Silva HJ. Aetiology of recurrent abdominal pain in a cohort of Sri Lankan children. J Paediatr Child Health 2008; 44(4): 195-200.
57. Walker LS, Lipani TA, Greene JW, Caines K, Stutts J, Polk DB, et al. Recurrent Abdominal Pain: Symptom Subtypes Based on the Rome II Criteria for Pediatric Functional Gastrointestinal Disorders. $J$ Pediatr Gastroenterol Nutr 2004; 38(2): 187-91.

58. Schurman JV, Friesen CA, Danda CE, Andre L, Welchert E, Lavenbarg T, et al. Diagnosing functional abdominal pain with the Rome II criteria: parent, child, and clinician agreement. J Pediatr Gastroenterol Nutr 2005; 41(3): 291-5.

59. Rasquin-Weber A, Hyman PE, Cucchiara S, Fleisher DR, Hyams JS, Milla PJ, et al. Childhood functional gastrointestinal disorders. Gut 1999; 45(Suppl 2): II60-8.

60. Rasquin A, Lorenzo C, Forbes D, Guiraldes E, Hyams JS, Staiano A, et al. Childhood functional gastrointestinal disorders: child/adolescent. Gastroenterology 2006; 130(5): 1527-37.

61. Fernando N, Perera N, Vaira D, Holton J. Helicobacter pylori in school children from the Western province of Sri Lanka. Helicobacter 2001; 6(2): 169-74.

62. Walker LS and Green JW. Children with recurrent abdominal pain and their parents: More somatic complaints, anxiety, depression than other patient families? J Pediatr Psychol 1989; 14(2): 231-43.

63. Devanarayana NM, de Silva DG, de Silva HJ. Gastric myoelectrical and motor abnormalities in children and adolescents with functional recurrent abdominal pain. $J$ Gastroenterol Hepatol 2008; 23(11): 1672-7.

64. Chen JD, McCallum RW (1994). Electrogastrographic parameters and their clinical significance. In: Chen JD, McCallum RW, ed. Electrogastrography: principals and applications. New York: Raven Press, 45-73.

65. Vreugdenhil G, Sinaasappel M, Bouquet J. A comparative study of the mouth to caecum transit time in children and adults using a weight adapted lactulose dose. Acta Paediatr Scand 1986; 75(3): 483-8.

66. Caride VJ, Prokop EK, Troncale FJ, Buddoura W, Winchenbach K, McCallum RW. Scintigraphic determination of small intestinal transit time: Comparison with the hydrogen breath technique. Gastroenterology 1984; 86 (4): $714-20$ 
67. Chen JD, Lin X, Zhang M, Torres-Pinedo RB, Orr WC. Gastric myoelectrical activity in healthy children and children with functional dyspepsia. Dig Dis Sci 1998; 43 (11): 2384-91.

68. Friesen CA, Lin Z, Hyman PE, Andre L, Welchert E, Schurman JV, et al. Electrogastrography in pediatric functional dyspepsia: relationship to gastric emptying and symptom severity. $J$ Pediatr Gastroenterol Nutr 2006; 42(3): 265-9.

69. Waldron B, Cullen PT, Kumar R, Smith D, Jankowski J, Hopwood D, et al. Evidence for hypomotility in non-ulcer dyspepsia: a prospective multifactorial study. Gut 1991; 32(3): $246-51$

70. Lu CL, Chen CY, Chang FY, Lee SD. Characteristics of small bowel motility in patients with irritable bowel syndrome and normal humans: an Oriental study. Clin Sci (Lond) 1998; 95(2): 165-9.

71. Monnikes H, Tebbe JJ, Hilderbrandt M, Arck P, Osmanoglou E, Rose M, et al. Role of stress in functional gastrointestinal disorders. Evidence for stress-induced alterations in gastrointestinal motility and sensitivity. Dig Dis 2001; 19(3): 201-11.
72. Chelimsky G, Boyle JT, Tusing L, Chelimsky TC. Autonomic abnormalities in children with functional abdominal pain: coincidence or etiology? J Pediatr Gastroenterol Nutr 2001; 33 (1): 47-53.

73. Olafsdottir E, Ellertsen B, Berstad A, Fluge G. Personality profiles and heart rate variability (vagal tone) in children with recurrent abdominal pain. Acta Paediatr 2001; 90(6): 632-7.

74. Duan LP, Zheng ZT, Li YN. A study of gastric emptying in non-ulcer dyspepsia using a new ultrasonographic method. Scand $J$ Gastroenterol 1993; 28(4): 355-60.

75. Prather CM, Camilleri M, Zinsmeister AR, McKinzie S, Thomforde G. Tegaserod accelerates orocaecal transit in patients with constipation-predominant irritable bowel syndrome. Gastroenterology 2000; 118(3): 463-8. 